\title{
Effects of combination PPARy agonist and angiotensin receptor blocker on glomerulosclerosis
}

\author{
Keizo Matsushita ${ }^{1,4}$, Hai-Chun Yang ${ }^{1,4}$, Manu M Mysore ${ }^{1,2}$, Jianyong Zhong ${ }^{1}$, Yu Shyr ${ }^{3}$, Li-Jun Ma ${ }^{1}$ and Agnes B Fogo
}

We previously observed that high-dose angiotensin receptor blocker (ARB) can induce regression of existing glomerulosclerosis. We also found that proliferator-activated recepto- $\gamma$ (PPAR $\gamma$ ) agonist can attenuate glomerulosclerosis in a nondiabetic model of kidney disease, with specific protection of podocytes. We now assessed effects of combination therapy with ARB and pioglitazone on established glomerulosclerosis. Sprague-Dawley male rats underwent 5/6 nephrectomy $(5 / 6 \mathrm{Nx})$ at week 0 and renal biopsy at week 8 . Rats were randomized to groups with equal starting moderate glomerulosclerosis, and treated with ARB, PPARY agonist (pioglitazone), combination or vehicle from weeks 8 to 12. Body weight, systolic blood pressure (SBP), and urinary protein (UP) were measured at intervals. In rats with established sclerosis, SBP, UP, and GS were equal in all groups at week 8 before treatment by study design. Untreated control rats had hypertension, decreased GFR, and progressive proteinuria and glomerulosclerosis at week 12. Only combination therapy significantly ameliorated hypertension and proteinuria. ARB alone or pioglitazone alone had only numerically lower SBP and UP than vehicle at week 12 . Both pioglitazone alone and combination had significantly less decline in GFR than vehicle. Combination-induced regression of glomerulosclerosis in more rats from weeks 8 to 12 than ARB or pioglitazone alone. In parallel, combination treatment reduced plasminogen activator inhibitor-1 expression and macrophage infiltration, and preserved podocytes compared with vehicle. These results were linked to increased $\mathrm{AT}_{2}$ receptor and Mas1 mRNA in the combination group. PPARy agonists in combination with ARB augment regression of glomerulosclerosis, with downregulation of injurious RAAS components vs PPAR $y$ alone, with increased anti-fibrotic/ healing RAAS components, enhanced podocyte preservation, and decreased inflammation and profibrotic mechanisms. Laboratory Investigation (2016) 96, 602-609; doi:10.1038/labinvest.2016.42; published online 21 March 2016

Chronic kidney disease (CKD) is characterized by a progressive loss in renal function with progressive scarring that affects all structures of the kidney. Angiotensin II, a key component of the renin-angiotensin-aldosterone system (RAAS), binds to $\mathrm{AT}_{1}$ or $\mathrm{AT}_{2}$ receptors. The classic $\mathrm{AT} 1$ receptor mediates vasoconstriction and promotes extracellular matrix synthesis both directly and via profibrotic factors such as transforming growth factor- $\beta$ (TGF- $\beta$ ) and plasminogen activator inhibitor-1 (PAI-1). ${ }^{1}$ The AT2 receptor is counterregulatory, contributing to vasodilatation and apoptosis. Various clinical studies have shown superior effects on progression of RAAS blockade with angiotensin I converting enzyme inhibitor (ACEI) and/or angiotensin II type I receptor blockers (ARB) $v s$ other nonspecific anti-hypertensive treatments. ${ }^{2}$ Unfortunately, administration of ARBs in doses considered sufficient to robustly block AT1 receptors often fails to provide effective blood pressure (BP) control and to protect against adverse cardiovascular events and diabetes. ${ }^{3,4}$ In our previous studies in the rat 5/6 Nx model, we showed that high-dose ARB-induced regression of existing glomerulosclerosis over 4 weeks, although 6-month treatment only ameliorated progression. ${ }^{5}$ Unfortunately, combination ACEI and ARB may be associated with adverse events, and renin inhibitors also had side effects in clinical trials. ${ }^{6,7}$ Thus, RAAS blockade alone is not sufficient to prevent ongoing progression of CKD and hypertension. Approaches to target additional pathways of sclerosis and in particular podocyte injury are therefore of particular interest.

Peroxisome proliferator-activated receptor- $\gamma(\operatorname{PPAR} \gamma)$ agonists are classically used to treat dyslipidemia and enhance insulin sensitivity in type II diabetic patients. PPAR $\gamma$ agonists, such as thiazolidinediones, activate PPAR $\gamma$, a ligand-activated

\footnotetext{
${ }^{1}$ Department of Pathology, Microbiology, and Immunology, Vanderbilt University Medical Center, Nashville, TN, USA; ${ }^{2}$ Louisiana State University Health Sciences Center, New Orleans, LA, USA and ${ }^{3}$ Center for Quantitative Sciences, Vanderbilt University Medical Center, Nashville, TN, USA

Correspondence: Dr AB Fogo, MD, Department of Pathology, Microbiology, and Immunology, Vanderbilt University Medical Center, MCN C3310, Nashville, TN 37232, USA. E-mail: agnes.fogo@vanderbilt.edu

${ }^{4}$ These authors contributed equally to this work.
}

Received 5 May 2015; revised 10 February 2016; accepted 18 February 2016 
nuclear transcription factor that dimerizes with the retinoid $\mathrm{X}$ receptor and then binds to the PPAR response element of target genes in the nucleus. ${ }^{8}$ We previously found that PPAR $\gamma$ agonists protect against glomerulosclerosis in nondiabetic models of CKD by reducing TGF- $\beta$, PAI- 1 , and macrophage infiltration. ${ }^{9,10}$ PPAR $\gamma$ agonists directly protected podocytes against injury, and maintained expression of nephrin and other key slit-diaphragm proteins. ${ }^{11}$

The multiple additional signal pathways potentially modulated by PPAR $\gamma$ agonists, beyond RAAS targets, point to possible benefits of combination interaction. We therefore assessed potential additional benefits and mechanisms of combination PPAR $\gamma$ agonist and ARB therapy in existing glomerulosclerosis.

\section{MATERIALS AND METHODS}

\section{Animals}

Adult male Sprague-Dawley rats (200-250 g; Charles River, Chicago, IL, USA) were studied. All protocols were approved by the Institutional Animal Care and Use Committee according to the National Institutes of Health guidelines. Rats were housed under normal conditions with a 12:12-h light-dark cycle at $21{ }^{\circ} \mathrm{C}$ with $40 \%$ humidity and 12 air exchanges per hour, standard rat chow ('5001' diet; rodent diet, $23.4 \%$ protein, $4.5 \%$ fat, $6.0 \%$ fiber, $0.40 \%$ sodium; Purina Laboratory, St Louis, MO, USA) and water ad libitum. Rats underwent 5/6 nephrectomy ( $\mathrm{Nx}$ ) by uninephrectomy on the right side and ligation of two or three branches of the left renal artery. This model is characterized by the development of early sclerosis, proteinuria, and hypertension by week 4 , with established sclerosis by week 8 , with ongoing progression to uremic death by 12-16 weeks.

Rats were randomized at week 8 after $5 / 6 \mathrm{Nx}$ to achieve similar levels in each group of systemic BP, urinary protein levels, and glomerulosclerosis, assessed by open renal biopsy, before treatment was started. Rats were then treated from weeks 8 to 12 after 5/6 Nx with the ARB TAK-491 (ARB, $3 \mathrm{mg} / \mathrm{kg} /$ day in drinking water, $n=6$ ), pioglitazone (Pio, $2.5 \mathrm{mg} / \mathrm{kg} /$ day in chow, $n=7)$, combination drug therapy $(\mathrm{ARB}+\mathrm{PIO}, n=7)$, or vehicle (vehicle, $n=7)$. Doses were based on previous studies in hypertensive kidney disease models. ${ }^{12}$

\section{Renal Function}

Functional studies were performed at baseline, weeks 4, 8, and 12 after 5/6 Nx. Systolic BP (SBP) was measured using a conscious tail-cuff method. Animals were placed in metabolic cages for collection of $24 \mathrm{~h}$ urine samples. Urine protein excretion was measured by Bio-Rad Protein Assay Kit (BioRad Laboratories, Hercules, CA, USA). Plasma and urine creatinine were measured at week 12 by Vitros CREA slides (Johnson \& Johnson Clinical Diagnostics, Rochester, NY, USA).

\section{Morphologic Assessment}

Kidney tissues were fixed in $4 \%$ paraformaldehyde/phosphate-buffered saline solution and routinely processed, and $3 \mu \mathrm{m}$ sections were cut and stained.

A semiquantitative score (glomerulosclerosis index, sclerosis index (SI)) was used to evaluate the degree of glomerulosclerosis. SI in each glomerulus was graded from 0 to $4+$ as follows: 0 defined as no lesion; $1+$ sclerosis of $<25 \%$ of kidney; $2+$ sclerosis between 25 and $50 \%$ of the glomerulus; $3+$ sclerosis between 50 and $75 \%$ of the glomerulus; and $4+$ sclerosis $>75 \%$ of the glomerulus. A whole kidney average sclerosis index for each rat was obtained by averaging scores from all glomeruli on PAS-stained sections. All sections were examined without knowledge of the treatment protocol. Change of sclerosis from biopsy to autopsy was calculated for each animal as previously described. ${ }^{10}$

\section{Immunohistochemistry}

Sections were deparaffinized and hydrated. For WT1 and $\mathrm{ED} 1$, sections were microwaved in citrate buffer $(\mathrm{pH}$ 6.0) for $5 \mathrm{~min}$. Endogenous peroxidase was quenched with $3 \%$ hydrogen peroxidase for $10 \mathrm{~min}$, and slides were then exposed to Power Block (BioGenex Laboratories, San Ramon, CA, USA) for $45 \mathrm{~min}$. The primary antibodies used were rabbit anti-rat WT1 (1:800; Santa Cruz), rabbit anti-rat PAI-1 $(20 \mu \mathrm{g} / \mathrm{ml}$; American Diagnostica, CT, USA), mouse anti-rat ED1 (1:50; Dako) and mouse anti-rat collagen I (1:400; Abcam, Cambridge, MA, USA). Sections were incubated overnight at $4{ }^{\circ} \mathrm{C}$. Immunoperoxidase staining was performed with the Vectastain ABC kit (Vector Laboratories, Burlingame, CA, USA) with diaminobenzidine as a chromogen. Hematoxylin was used as a counterstain.

WT1 and ED1-positive nuclei per glomerulus were counted, and localization was assessed based on cell anatomical location and morphology. Collagen I stained slides were scanned by using the Aperio CSO system (Leica Biosystems, Buffalo Grove, IL, USA). The positive area was analyzed by using Aperio Imagescope software. All sections were examined without knowledge of the treatment protocol.

\section{Western Blot}

Frozen kidney tissue samples were transferred in RIPA buffer containing 1:100 phosphatase inhibitor cocktail I, 1:100 phosphatase inhibitor cocktail II (Sigma, St Louis, MO, USA), and 1:100 proteinase inhibitor cocktail tablet (Roche Diagnostics, Mannheim, Germany). Samples were homogenized and centrifuged, and the protein concentration was measured using the DC Protein Assay kit (Bio-Rad Laboratories, Hercules, CA, USA). PAI-1 (1:400; R\&D Systems, Minneapolis, MN, USA), AT ${ }_{1} \mathrm{R}(1: 400 ; \mathrm{Abcam}), \mathrm{AT} 2 \mathrm{R}$ (1:1000; Abcam), and GAPDH (1:500; Cell Signaling) were detected by using the corresponding antibody overnight at $4{ }^{\circ} \mathrm{C}$. Horseradish peroxidase-labeled anti-goat or anti-rabbit IgG secondary antibody ( $1: 2500$ in $5 \%$ milk TBS-Tween 20$)$ was added and incubated at room temperature for $45 \mathrm{~min}$. 
a

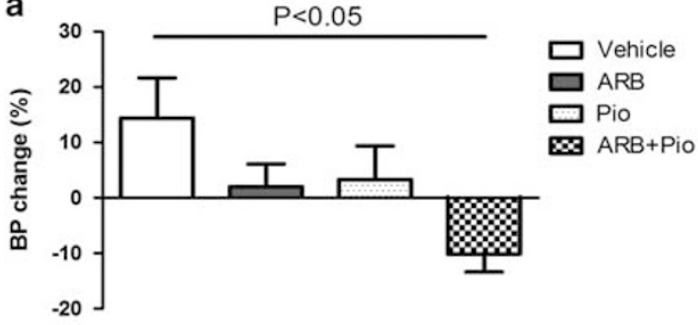

b

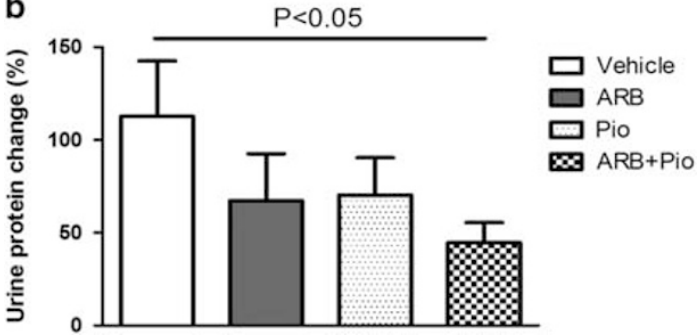

Figure 1 Combination therapy decreased SBP and proteinuria more than monotherapy. (a) Only combination therapy significantly decreased SBP. (b) Combination therapy, but not ARB or Pio alone, prevented increase of proteinuria from weeks 8 to 12 . ARB, angiotensin receptor blocker; SBP, systolic blood pressure.

Protein bands on western blots were visualized by ECL Plus (Amersham, Arlington Heights, IL, USA) according to the manufacturer's instructions and were developed on film.

\section{PPARY Activity}

Frozen kidney tissue samples were transferred in $1 \times$ hypotonic buffer supplemented with 1M DTT and detergent. Samples were homogenized and centrifuged, and nuclear material was extracted with Complete Lysis Buffer using a Nuclear Extraction Kit (Active Motif, Carlsbad, CA, USA). Protein concentration was measured using a BSA assay (Active Motif) and PPAR $\gamma$ activity was measured using a TransAM PPAR $\gamma$ kit (Active Motif). ${ }^{9}$

\section{8-isoprostane Expression}

8-isoprostane expression in kidney was measured by the EIA kit (Oxford Biomedical Research, Rochester Hills, MI, USA).

\section{Quantitative Real-Time PCR}

Reverse transcription was performed using the TaqMan Reverse Transcription Kit (Applied Biosystems, Branchburg, NJ, USA) in a total reaction volume of $80 \mu \mathrm{l}(2 \mu \mathrm{g}$ total RNA, $5 \mathrm{mM} \mathrm{MgCl} 2,1 \mathrm{mM}$ dNTPs, $1 \mathrm{U} / \mu$ l RNase inhibitor, $2.5 \mu \mathrm{M}$ random hexamers, and $2.5 \mathrm{U} / \mu \mathrm{l} \mathrm{MuLV}-\mathrm{RT}$ ) for $30 \mathrm{~min}$ at $42{ }^{\circ} \mathrm{C}$. Quantitative real-time PCR was performed in a total reaction volume of $25 \mu \mathrm{l}$ using $\mathrm{iQ}$ SYBR Green Supermix (Bio-rad, Hercules, CA, USA), $1 \mu \mathrm{l}$ cDNA, and $500 \mathrm{nM}$ forward and reverse primers. IL-1, IL-6, renin, angiotensinogen, ACE, AT1R, AT2R, and Mas1 primers were from SABiosciences Corporation (Frederick, MD, USA).
Quantitative real-time PCR was carried out using the iCycler iQ Multi-Color Real-Time PCR Detection System (Bio-Rad) with the following cycling parameters: polymerase activation for $3 \mathrm{~min}$ at $95^{\circ} \mathrm{C}$ and amplification for 40 cycles of $20 \mathrm{~s}$ at $95^{\circ} \mathrm{C}, 20 \mathrm{~s}$ at $60^{\circ} \mathrm{C}$, and $40 \mathrm{~s}$ at $72^{\circ} \mathrm{C}$. Following amplification, a final melting curve was obtained for each sample by cooling the reaction mixture to $55^{\circ} \mathrm{C}$ and then slowly heating it to $95^{\circ} \mathrm{C}$ at $0.2^{\circ} \mathrm{C} / \mathrm{s}$. Experimental cycle threshold (Ct) values were normalized to GAPDH measured on the same plate, and fold differences in gene expression were determined by using the $2^{-\triangle \triangle \mathrm{Ct}}$ method.

\section{Statistical Analysis}

Data are expressed as means \pm s.e., and as change in each rat from start of intervention till killing. Differences among groups were examined by one-way ANOVA followed by Bonferroni's test. Nonparametric data were compared by Mann-Whitney $U$-test. $P$-values $<0.05$ were considered significant.

\section{RESULTS}

\section{Combination of PPARY Agonist with ARB-Protected Renal Function}

SBP increased from $194.6 \pm 13.2$ at week 8 to $217.8 \pm 13.3 \mathrm{~mm} \mathrm{Hg}$ at week 12 in the vehicle group. Both ARB and pioglitozone numerically blunted this increase in BP (ARB 2.0 $\pm 4.1 \%$, Pio $3.3 \pm 6.0 \%$, vs vehicle $14.4 \pm 7.2 \%$ change week 12 vs week 8 , pNS). Only combination treatment significantly decreased SBP compared with baseline at week 8 (ARB+Pio $-10.1 \pm 3.2 \%$, vs vehicle, $P<0.05)$ (Figure 1a and Table 1 ).

Proteinuria increased from $258.3 \pm 37.3$ to $428.8 \pm 69.5 \mathrm{mg}$ per $24 \mathrm{~h}$ in the vehicle group. Combination treatment, but not $\mathrm{ARB}$ or pioglitazone alone, blunted the increase in proteinuria (ARB+Pio $44.6 \pm 10.8 \%$, vs vehicle $112.7 \pm 29.8 \%$ change $v s$ wk $8, P<0.05$ ) (Figure $1 \mathrm{~b}$ and Table 1 ).

Serum creatinine increased from weeks 8 to 12 in all groups. Only combination treatment significantly ameliorated the rise of Scr (ARB+Pio $21.5 \pm 7.7 \%$, vs vehicle $47.6 \pm 6.4 \%$ change $v s$ wk $8, P<0.05$ ) (Figure $2 \mathrm{a}$ and Table 1). Similarly, creatinine clearance decreased from weeks 8 to 12 in vehicle. Both pioglitazone and combination treatment protected renal function (change in Ccr, Pio $-27.8 \pm 10.5 \%$, ARB+Pio $-29.0 \pm 10.3 \%$, vs vehicle $-58.2 \pm 5.2 \%, P<0.05$ ), while ARB alone did not have significant effect $v s$ vehicle $(-34.9 \pm 14.1 \%)$ (Figure $2 \mathrm{~b}$ and Table 1$)$.

\section{Effects on Progression}

Glomerulosclerosis was similar at biopsy in all treatment groups by study design. At week 12 after $5 / 6 \mathrm{Nx}$, vehicle rats showed progressive glomerulosclerosis, as evidenced by an average $176.7 \%$ increase in the SI from biopsy to autopsy. In contrast, ARB alone or Pio alone ameliorated progression of glomerulosclerosis $v s$ vehicle (ARB 98.4 $\pm 59.3 \%$, Pio $59.8 \pm 25.9 \%$ vs vehicle $176.7 \pm 76.2 \%$, change in SI from biopsy to autopsy, pNS). Combination therapy reduced the 
Table 1 Functional and structural parameters from week 8 and 12

\begin{tabular}{|c|c|c|c|c|c|c|c|c|}
\hline & \multicolumn{4}{|c|}{ W8 } & \multicolumn{4}{|c|}{ W12 } \\
\hline & Vehicle & ARB & Pio & $\mathrm{ARB}+\mathrm{Pio}$ & Vehicle & ARB & Pio & $\mathrm{ARB}+\mathrm{Pio}$ \\
\hline BW (g) & $344.3 \pm 6.1$ & $330.0 \pm 9.5$ & $335.4 \pm 8.0$ & $356.7 \pm 9.4$ & $361.4 \pm 15.7$ & $348.7 \pm 15.4$ & $364.1 \pm 11.8$ & $395.4 \pm 11.8^{*}$ \\
\hline $\mathrm{BP}(\mathrm{mmHg})$ & $194.6 \pm 13.2$ & $191.5 \pm 3.2$ & $197.0 \pm 11.2$ & $194.1 \pm 10.1$ & $217.8 \pm 13.3$ & $195.5 \pm 9.1$ & $201.3 \pm 11.2$ & $176.3 \pm 8.3^{\#}$ \\
\hline UP (mg/24 h) & $258.3 \pm 37.3$ & $267.5 \pm 38.8$ & $251.5 \pm 17.9$ & $242.9 \pm 29.2$ & $428.8 \pm 69.5$ & $425.2 \pm 72.8$ & $420.3 \pm 45.5$ & $355.0 \pm 49.0$ \\
\hline $\operatorname{Scr}(\mathrm{mg} / \mathrm{dl})$ & $1.93 \pm 0.30$ & $1.98 \pm 0.20$ & $1.68 \pm 0.25$ & $1.62 \pm 0.17$ & $4.18 \pm 1.0$ & $3.65 \pm 1.17$ & $2.34 \pm 0.31$ & $2.17 \pm 0.28$ \\
\hline $\mathrm{Ccr}(\mathrm{ml} / \mathrm{min}$ per $100 \mathrm{~g} \mathrm{BW})$ & $0.14 \pm 0.043$ & $0.11 \pm 0.015$ & $0.13 \pm 0.016$ & $0.14 \pm 0.015$ & $0.077 \pm 0.082$ & $0.079 \pm 0.025$ & $0.091 \pm 0.012$ & $0.097 \pm 0.019$ \\
\hline SI & $0.82 \pm 0.28$ & $0.83 \pm 0.13$ & $0.86 \pm 0.16$ & $0.85 \pm 0.21$ & $1.67 \pm 0.35$ & $1.47 \pm 0.42$ & $1.36 \pm 0.30$ & $0.70 \pm 0.23^{\#}$ \\
\hline$W T 1^{+}$cell density $\left(\times 10^{-3} / \mu \mathrm{m}^{2}\right)$ & $1.33 \pm 0.18$ & $1.31 \pm 0.13$ & $1.41 \pm 0.18$ & $1.41 \pm 0.17$ & $0.84 \pm 0.07$ & $0.90 \pm 0.09$ & $0.88 \pm 0.12$ & $1.08 \pm 0.10^{\#}$ \\
\hline
\end{tabular}

$\mathrm{ARB}$, angiotensin receptor blocker; $\mathrm{BP}$, blood pressure; BW, body weight; Ccr, creatinine clearance; SI, sclerosis index; UP, urinary protein.

*, vs ARB, at week $12, P<0.05 ;$, vs vehicle, at week $12, P<0.05$.
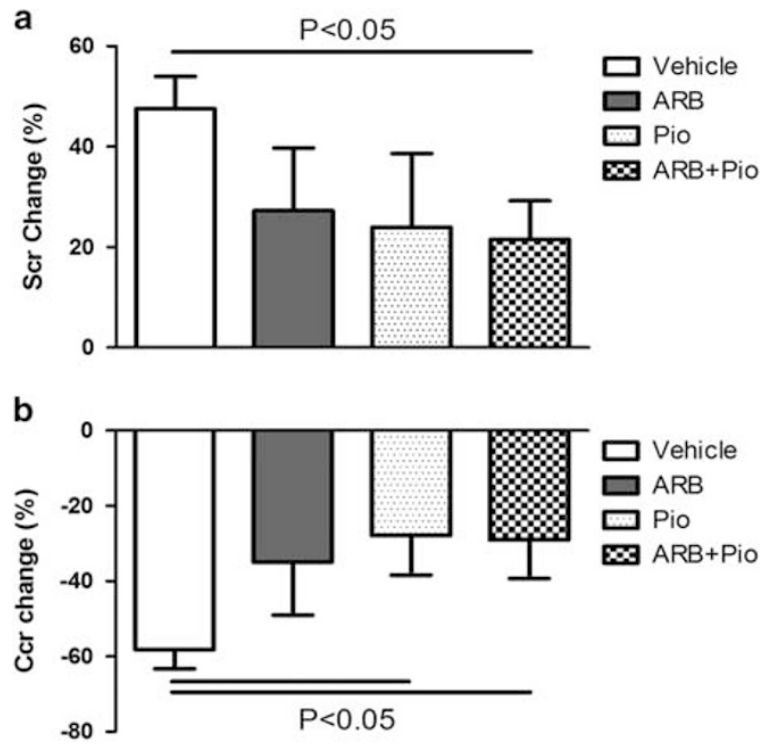

Figure 2 Both PPARy agonist and combination treatment protected renal function. Serum creatinine (a) increased and $\mathrm{Ccr}$ (b) decreased from weeks 8 to 12 in all groups. Pio preserved $\mathrm{Ccr}$, but only combination treatment prevented both the increase of Scr and decrease of $\mathrm{Ccr}$. Ccr, creatinine clearance.

extent of glomerulosclerosis at week 12 (ARB+Pio $-11.7 \pm 24.8 \%$, vs vehicle, $P<0.05$ ) (Figures $3 \mathrm{a}$ and $\mathrm{b}$ and Table 1). Regression, defined as reduction of sclerosis from biopsy to autopsy in the same rat, occurred in $5 / 7$ rats in the $\mathrm{ARB}+\mathrm{Pio}$ group, compared with $2 / 6$ in $\mathrm{ARB}$ and $1 / 7$ in vehicle and Pio groups (ARB+Pio vs vehicle, $P<0.05$; ARB vs vehicle, pNS) (Figure 3c).

Interstitial fibrosis, measured by collagen I staining, was significantly reduced by combination therapy (ARB+Pio $9.90 \pm 0.53$, vs vehicle $12.97 \pm 0.92 \%, P<0.05$ ), but not by $\mathrm{ARB}$ or Pio alone (ARB 12.64 \pm 1.20 , Pio $12.42 \pm 1.04 \%$, vs vehicle, pNS) (Figure 4a).
PAI-1, a molecule that can inhibit matrix degradation, was not significantly changed by ARB or Pio alone vs vehicle, while combination therapy resulted in significantly less PAI-1 expression when compared with vehicle (ARB+Pio $0.04 \pm 0.01$, vs vehicle $0.14 \pm 0.03$, PAI- 1 ratio to $\beta$-actin, $P<0.05$ ) (Figure $4 \mathrm{~b}$ ). 8-isoprostane, a marker for reactive oxygen species, increased in vehicle-treated $5 / 6 \mathrm{Nx}$ kidneys $(894.63 \pm 7.74 \mathrm{pg} / \mathrm{mg})$ compared with normal kidneys $(207.22 \pm 71.28 \mathrm{pg} / \mathrm{mg})$, with no further effect by treatment (ARB $800.19 \pm 117.99$, Pio $978.95 \pm 275.08$, and $A R B+P i o$ $913.60 \pm 90.83 \mathrm{pg} / \mathrm{mg}$, respectively).

\section{Effects on Inflammation and Podocytes}

Macrophage staining was most prominent in glomeruli of vehicle rats at week $12(5.35 \pm 1.76 \mathrm{ED} 1+$ cells/glom $)$. Treatment with pioglitazone did not significantly change infiltrating glomerular macrophages $(3.43 \pm 1.18$ ED1+ cells/glom), in contrast to a significant decrease in macrophage infiltration in the ARB+Pio rats $(1.54 \pm 0.41 \mathrm{ED} 1+$ cells/glom, $v s$ vehicle, $P<0.05$ ) (Figure 5a). IL-1 and IL-6, measured in renal cortex by real-time PCR, did not show any difference among groups (data not shown).

Density of WT1-positive cells in the glomeruli was taken as an indicator of differentiated podocytes. At week 8, glomerular WT1-positive cell density was reduced similarly in all groups $v s$ normal baseline. At week 12, the vehicle group showed $0.84 \pm 0.07 \times 10^{-3} / \mu \mathrm{m}^{2} \mathrm{WT} 1^{+}$cells in glomeruli. ARB alone or Pio alone was not different $v s$ vehicle (ARB $0.90 \pm 0.09$, Pio $0.88 \pm 0.12 \times 10^{-3} / \mu \mathrm{m}^{2}$, vs vehicle, $\mathrm{pNS}$ ), but the ARB+Pio combination resulted in higher density of $\mathrm{WT}^{+}$glomerular cells $\left(1.08 \pm 0.10 \times 10^{-3} / \mu \mathrm{m}^{2}, v s\right.$ vehicle, $P<0.05$ ) (Figure 5b).

\section{Effects on PPARY Activity and RAAS Components}

Kidney cortical PPAR $\gamma$ activity was numerically increased in $\mathrm{ARB}$ compared with vehicle at week 12 (ARB $0.19 \pm 0.03$, $v s$ vehicle $0.11 \pm 0.02, \mathrm{pNS})$. Pioglitazone alone and 
a
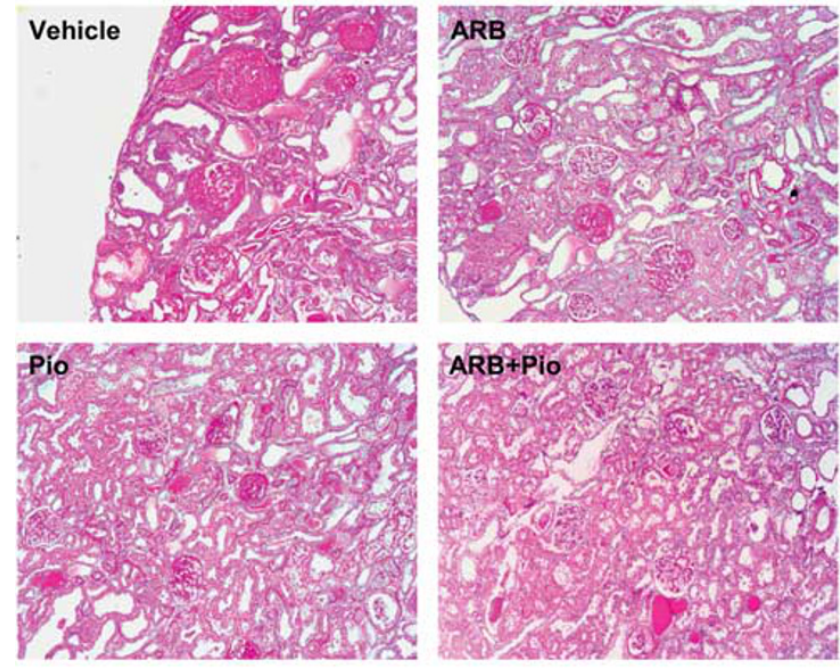

b

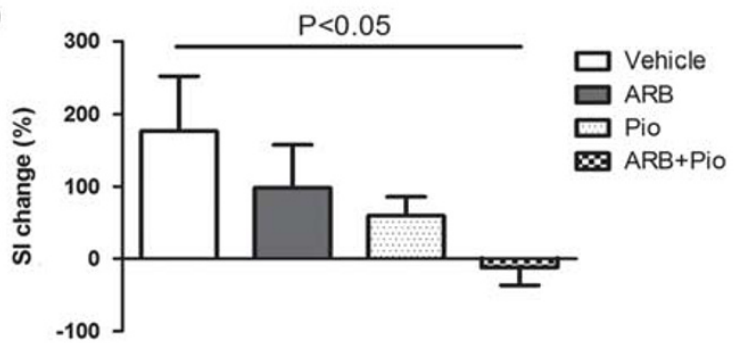

C

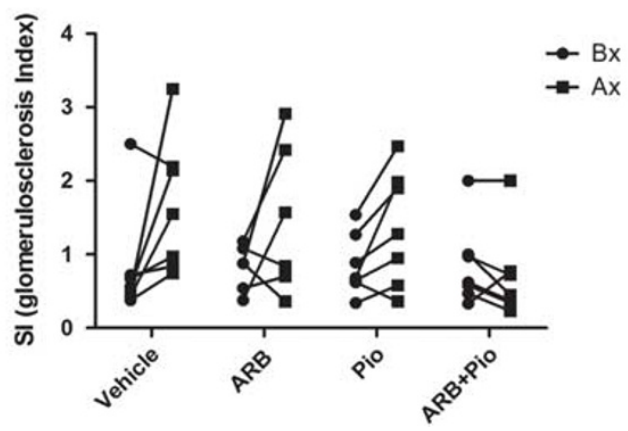

Figure 3 Combination therapy prevented the progression of glomerulosclerosis. Compared with the vehicle 5/6 Nx group, PPARy agonist (Pio) and ARB alone ameliorated glomerulosclerosis (a; PAS staining, $\times 200$ ), but combination therapy markedly reduced the extent of glomerulosclerosis at week 12. (b) Regression, defined as reduction of sclerosis from biopsy in the same rat (Bx, circles) to autopsy ( $A x$, squares), occurred in 5/7 rats in the Combination group, compared with 2/6 in ARB and $1 / 7$ each in vehicle and PPARy groups. (c) ARB, angiotensin receptor blocker; PPAR $\gamma$, proliferator-activated receptor- $\gamma$.

combination treatment showed significantly more activated PPAR $\gamma$ in the kidney (Pio $0.24 \pm 0.03, \mathrm{ARB}+\mathrm{Pio} 0.25 \pm 0.05 v s$ vehicle, $P<0.05)$ (Figure 6a).

Combination treatment numerically decreased $\mathrm{AT}_{1} \mathrm{R}$ protein expression (ARB+Pio $0.49 \pm 0.09$ vs vehicle $1.09 \pm 0.49, \mathrm{pNS})$ and pioglitazone numerically increased $\mathrm{AT}_{2} \mathrm{R}$ ( $\mathrm{ARB}+\mathrm{Pio} 1.85 \pm 0.34$ vs vehicle $1.34 \pm 0.22$, pNS),
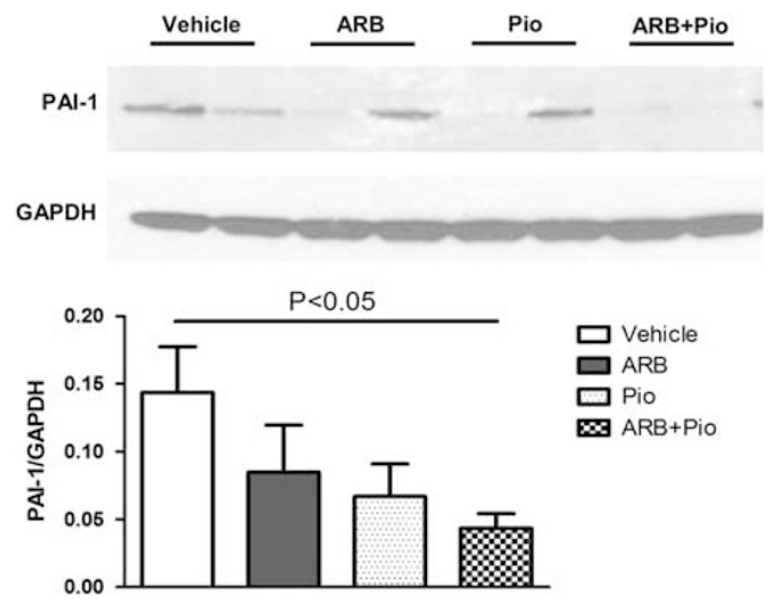

Figure 4 Combination therapy reduced PAI-1 expression. Both ARB and PPARy agonist (Pio) alone showed a trend to reduce kidney cortical PAl-1 protein expression, while combination therapy showed significantly less PAl-1 expression when compared with vehicle. ARB, angiotensin receptor blocker; PPAR $\gamma$, proliferator-activated receptor- $\gamma$.

while $A R B$ did not change the $\mathrm{AT}_{1} \mathrm{R}(0.71 \pm 0.20)$ and $\mathrm{AT}_{2} \mathrm{R}$ $(1.37 \pm 0.21)$ protein expression. Pioglitazone alone significantly enhanced renin mRNA expression and reduced ACE mRNA expression vs vehicle. The combination group had lower renin mRNA than pioglitazone alone. $\mathrm{AT}_{2} \mathrm{R}$ and Mas1, an Ang (1-7) receptor, mRNA expressions were increased only in the combination groups compared with the vehicle. Angiotensinogen and $\mathrm{AT}_{1} \mathrm{R}$ mRNA were not different among groups (Figure 6b).

\section{DISCUSSION}

Treatment of $\mathrm{CKD}$ has relied on reducing proteinuria, normalizing BP, and antagonism of the RAAS. However, these approaches have mainly slowed progression of CKD in most patients. Our previous studies have shown that highdose ARB, beyond BP control, can induce regression of glomerulosclerosis in animal models over 4 weeks. ${ }^{13}$ However, over 6-month follow-up, high-dose ARB merely ameliorated progression in the rat 5/6 Nx model..$^{5}$ In this study, PPAR $\gamma$ agonist in addition to ARB, was more effective than either alone in ameliorating progression and even regressing existing glomerulosclerosis. In particular, only combination treatment had beneficial effects on systemic BP, proteinuria, GFR, glomerulosclerosis index, and PAI-1. Mechanisms of combination therapy included decreased inflammation and preservation of differentiated podocytes.

ARB affects the PPAR $\gamma$ system. Classic ARBs have little direct effect on PPAR $\gamma$ expression or activity, but some ARBs, such as telmisartan, are also partial agonists of PPAR $\gamma$, which may provide more protection in patients with complicated diabetes or evidence for coronary artery disease without heart failure. ${ }^{14}$ Azilsartan, the ARB used in this study, is a potent AT1 receptor antagonist that is structurally similar to 
a
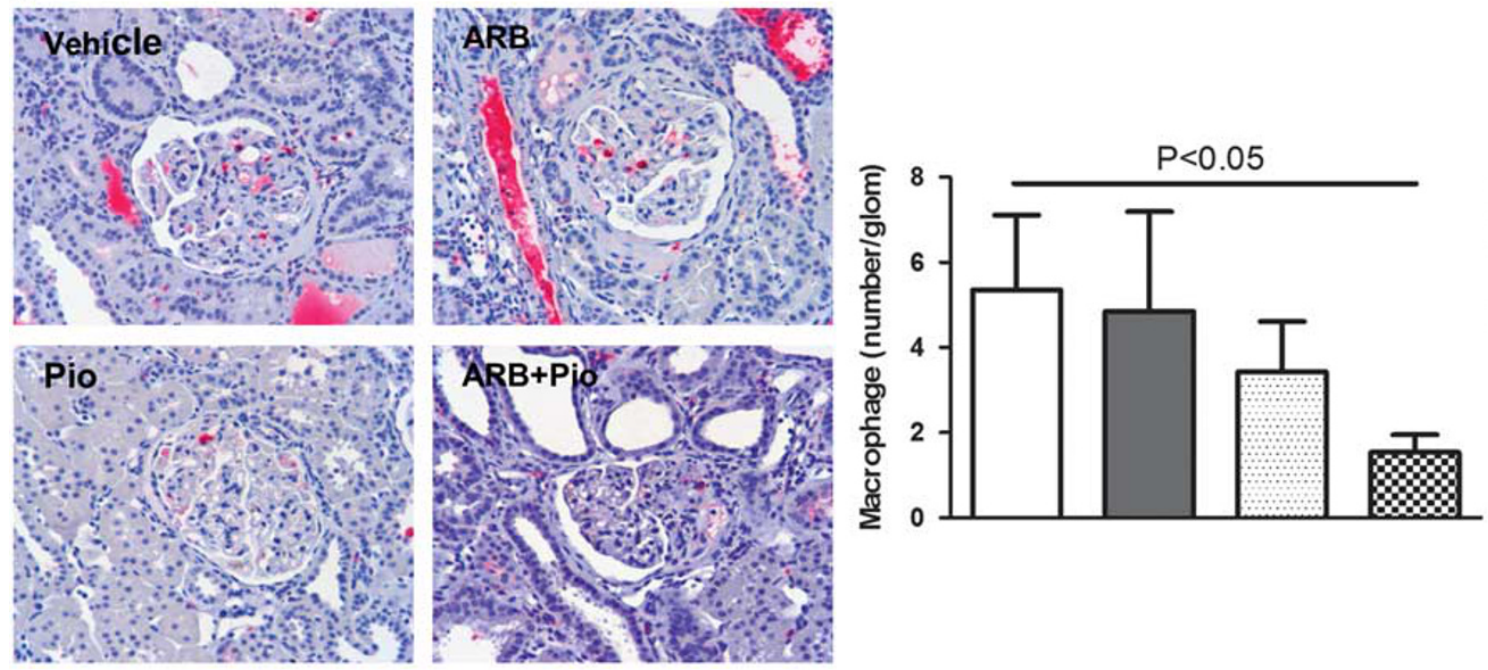

b
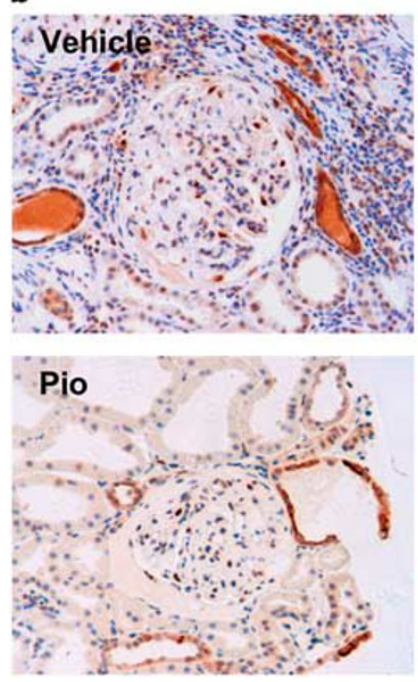
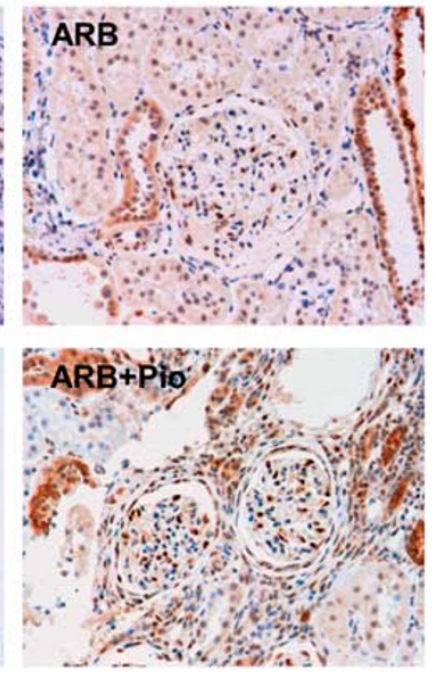
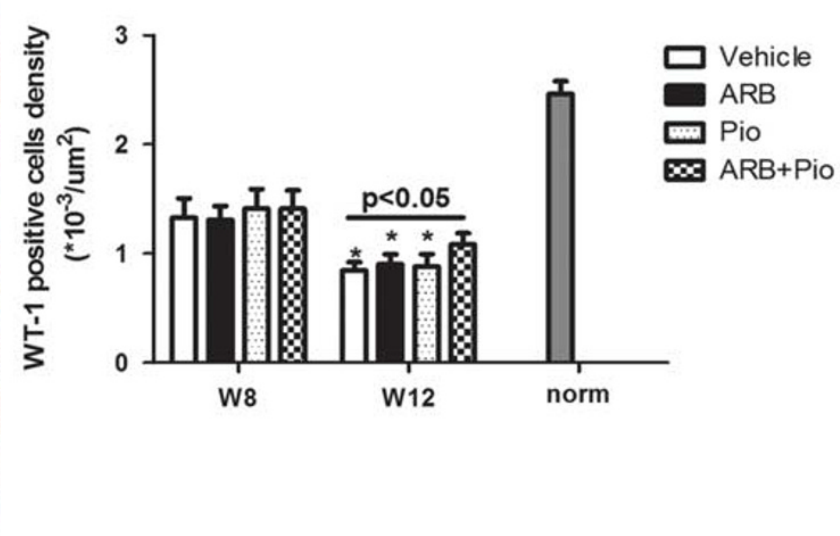

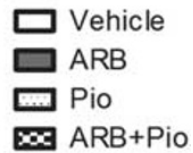

ARB+Pio

Figure 5 Combination therapy reduced inflammation and preserved differentiated podocytes. (a) Macrophages, stained by ED1, were increased in glomeruli of vehicle at week 12. Treatment with PPAR $\gamma$ agonist did not significantly decrease infiltrating glomerular macrophages. There was a remarkable decrease in macrophage infiltration in the combination group. (b) At week 8, before treatment, WT1-positive cell density, a marker of differentiated podocytes, was similarly decreased in fall our groups compared with normal kidney. At week 12, vehicle, ARB and Pio groups had further reduced WT1 density ( ${ }^{*} P<0.05$ compared with week 8 ), while combination therapy preserved WT1-positive cell. ARB, angiotensin receptor blocker; PPAR $\gamma$, proliferator-activated receptor- $\gamma$.

candesartan except for bearing a 5-oxo-1,2,4-oxadiazole moiety in place of a tetrazole ring. Azilsartan is less acidic and more lipophilic than candesartan and in preclinical studies has been shown to be significantly more potent than candesartan in improving glucose tolerance and tissue glucose metabolism. ${ }^{12}$ In cell-based receptor transactivation studies in vitro, azilsartan appears to have little or no direct effect on PPAR $\gamma$ activity. ${ }^{12}$ However, in a mouse model of type II diabetes, oral administration of very low doses of azilsartan significantly increased $\operatorname{PPAR} \gamma$ gene expression in adipose tissue. $^{12}$ In our study, this ARB showed a trend to increase PPAR $\gamma$ activity, but still far lower than that seen with pioglitazone. The combination of azilsartan and pioglitazone showed enhanced renal protection $v s$ the ARB alone, suggesting maximal PPAR $\gamma$ activity may provide extra benefit.

Conversely, PPAR $\gamma$ agonists affect the RAAS. In vitro, $\operatorname{PPAR} \gamma$ activation reduced AngII production in mesangial cells. ${ }^{15}$ PPAR $\gamma$ agonists also downregulated $\mathrm{AT}_{1} \mathrm{R}$ expression in proximal tubular epithelial and vascular smooth muscle cells with inhibition of ERK1/2 activation and attenuated NF- $\kappa$ B activation. ${ }^{16-18}$ Further, in $\mathrm{AT}_{1 \mathrm{a}}$ receptor-overexpressing HEK 293 cells, PPAR $\gamma$ agonist stimulated this receptor to induce endogenous $\beta$ arr $1 / 2$ recruitment and $\mathrm{AT}_{1 \mathrm{a}} \mathrm{R}$ internalization without $\mathrm{Gq}$ protein activation. ${ }^{19}$ In our study, we did not detect change of $\mathrm{AT}_{1} \mathrm{R}$ expression, but can not exclude a potential effect of PPAR $\gamma$ on AT1R activity 

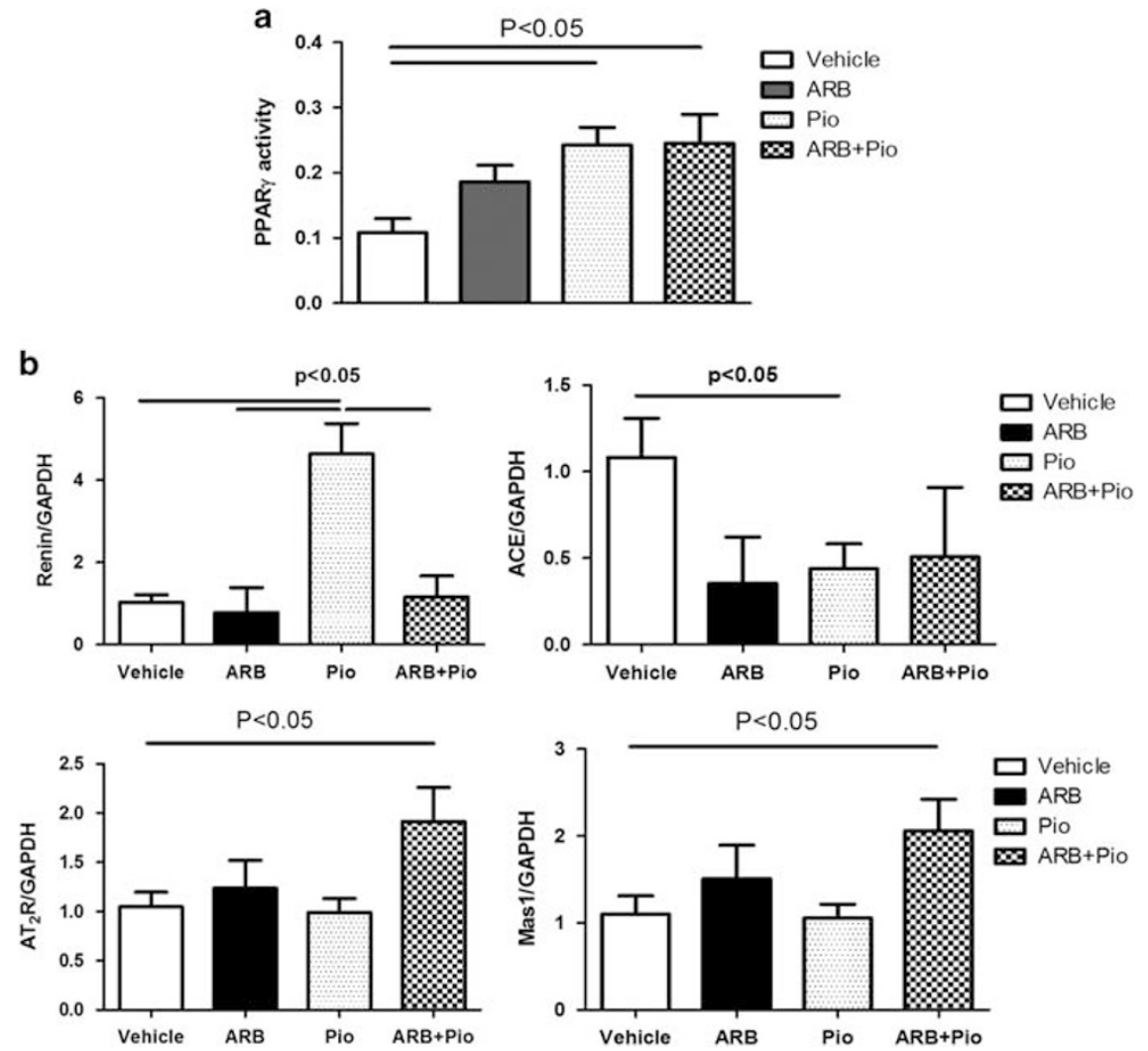

Figure 6 Interactions of PPARy agonists and ARB. (a) PPARy agonist and combination treatment-activated PPARy in the kidney, while ARB alone did not significantly increase PPARY activity. (b) PPARY agonists induced renin, but reduced ACE mRNA expressions. Combination treatment significantly increased $\mathrm{AT}_{2} \mathrm{R}$ and Mas1 mRNA expressions, while either therapy alone had no effect compared with vehicle. $\mathrm{ACE}$, angiotensin I converting enzyme; ARB, angiotensin receptor blocker; PPAR $\gamma$, proliferator-activated receptor $\gamma$.

through other pathways, such as $\mathrm{G}$ protein signaling. ${ }^{20} \mathrm{~A}$ change in balance of AT1 vs AT2 receptor could also influence progression of renal disease. We showed previously that AT2 blockade prevented beneficial effects of AT1 blockade by $\mathrm{ARB}$, supporting a beneficial role of the AT2 receptor. ${ }^{21}$ In the current study, PPAR $\gamma$ agonist showed a trend to reduce $\mathrm{AT}_{1} \mathrm{R}$ and upregulate $\mathrm{AT}_{2} \mathrm{R}$ protein levels, but had no effect on mRNA. We also found that PPAR $\gamma$ agonist significantly induced renin expression. Two newly described mechanisms are of relevance in this regard. First, the recently identified $\operatorname{PPAR} \gamma$ target sequence Pal3 is specific for the human renin gene and mediates exceptionally high sensitivity to transactivation. ${ }^{22}$ In addition, PPAR $\gamma$ has potentiating effects on cAMP signaling in renin-producing cells. ${ }^{23}$ The reduced ACE by $\operatorname{PPAR} \gamma$ agonist is also consistent with previous reports. $^{24}$

Combination of ARB and PPAR $\gamma$ agonist enhanced renal protection in the current study. All resident cells in glomeruli, including podocytes, express PPAR $\gamma$, AT receptors and PAI-1 after glomerular injury. Some infiltrating cells, such as macrophages, also express AT receptors and PAI- 1 . The enhanced renal protection by combination intervention may be related to interactions of the RAAS and PPAR $\gamma$, and involve effects on both systemic and cell functions affected by $\mathrm{ARB}$ and PPAR $\gamma$ agonist.

Of note, the anti-hypertensive effect of the combination therapy was significantly greater than that of the monotherapy. ARBs have direct anti-hypertensive effects. However, PPAR $\gamma$ agonist attenuated the development of hypertension in Dahl salt-sensitive rats and inhibited proliferation of renal arteriolar smooth muscle cells. ${ }^{25}$ Furthermore, PPAR $\gamma$ agonist also ameliorated endothelial dysfunction of afferent arterioles in Zucker obese rats and diet-induced type 2 diabetic mice. ${ }^{26,27}$ PPAR $\gamma$ agonist dilated not only the afferent but also the efferent arterioles in an ex vivo study. ${ }^{28}$ Improved endothelial function in intrarenal arteries and arterioles, accompanied by a fall in systemic BP, may account for the enhanced effects on proteinuria by the ARB plus PPAR $\gamma$ agonist combination therapy. ARBs may reduce proteinuria through functional hemodynamic effects, and also have direct beneficial effects on podocytes. ${ }^{29,30}$ We also observed additional benefits on structural injury by combination therapy, with less progression and preserved glomerular WT1 positivity, a marker of differentiated podocytes, compared with monotherapy. PPAR $\gamma$ agonists have direct effects on podocytes, with reduced apoptosis and injury and improved podocyte differentiation in vitro. ${ }^{31}$ Although 
combination treatment did not induce additional PPAR $\gamma$ activity, renin was decreased compared with $\operatorname{PPAR} \gamma$ agonist alone. Combination treatment also further increased $\mathrm{AT}_{2} \mathrm{R}$ and Mas1 expression, which may thus be another mechanism for the further benefit, with AT2 and Ang(1-7) implicated in repair/anti-fibrotic responses.

Combination therapy with losartan and pioglitazone has previously shown added effects in improving structure and function in rats with metabolic syndrome. ${ }^{32} \operatorname{PPAR} \gamma$ agonist also enhanced the renoprotective effects of an ARB in patients with diabetic nephropathy, which could in part relate to improved control of diabetes. ${ }^{33}$ Of note, our study shows that combination of PPAR $\gamma$ agonist and ARB induced more regression of glomerulosclerosis than monotherapy, linked to enhanced podocyte preservation, decreased glomerular inflammation and decreased profibrotic PAI-1, and increased $\mathrm{AT}_{2} \mathrm{R}$ and Mas1 expression, potential mediators of healing. We conclude that a rational choice of combined interventions to augment dampening of the multiple injury pathways activated in progressive kidney disease can achieve additional benefits on structure and function. It was also supported by O’Brien center grant (P30 DK079341, ABF).

\section{ACKNOWLEDGMENTS}

We thank Ellen Donnert for expert technical assistance. This work was supported in part by a grant from Takeda Pharmaceuticals USA and by a grant from NIDDK DK 56942 (ABF).

\section{DISCLOSURE/CONFLICT OF INTEREST}

The authors declare no conflict of interest.

1. Eddy $A A$, Fogo $A B$. Plasminogen activator inhibitor-1 in chronic kidney disease: evidence and mechanisms of action. J Am Soc Nephrol 2006;17:2999-3012.

2. Fogo AB. Mechanisms of progression of chronic kidney disease. Pediatr Nephrol 2007;22:2011-2022.

3. Oparil S, Silfani TN, Walker JF. Role of angiotensin receptor blockers as monotherapy in reaching blood pressure goals. Am J Hypertens 2005;18:287-294.

4. Yusuf S, Teo KK, Pogue J et al. Telmisartan, ramipril, or both in patients at high risk for vascular events. N Engl J Med 2008;358:1547-1559.

5. Albertazzi V, Yang H-C, Ma L-J et al. Sustained regression and improved survival with high dose ARB in 5/6 nephrectomy rats. J Am Soc Nephrol 2008;19:193A.

6. Parving $\mathrm{HH}$, Persson $\mathrm{F}$, Lewis JB et al. Aliskiren combined with losartan in type 2 diabetes and nephropathy. N Engl J Med 2008;358: 2433-2446.

7. Fried LF, Emanuele $\mathrm{N}$, Zhang JH et al. Combined angiotensin inhibition for the treatment of diabetic nephropathy. N Engl J Med 2013;369: 1892-1903.

8. Thomas MC, Jandeleit-Dahm KA, Tikellis C. The renoprotective actions of peroxisome proliferator-activated receptors agonists in diabetes. PPAR Res 2012;2012:456529.

9. Yang HC, Deleuze S, Zuo Y et al. The PPARgamma agonist pioglitazone ameliorates aging-related progressive renal injury. J Am Soc Nephrol 2009;20:2380-2388.

10. Ma LJ, Marcantoni C, Linton MF et al. Peroxisome proliferator-activated receptor-gamma agonist troglitazone protects against nondiabetic glomerulosclerosis in rats. Kidney Int 2001;59:1899-1910.

11. Kanjanabuch T, Ma LJ, Chen J et al. PPAR-gamma agonist protects podocytes from injury. Kidney Int 2007;71:1232-1239.

12. Iwai $M$, Chen $R$, Imura $Y$ et al. TAK-536, a new AT1 receptor blocker, improves glucose intolerance and adipocyte differentiation. Am J Hypertens 2007;20:579-586.
13. Ma $\mathrm{L}$, Nakamura $\mathrm{S}$, Aldigier JC et al. Regression of glomerulosclerosis with high-dose angiotensin inhibition is linked to decreased plasminogen activator inhibitor-1. J Am Soc Nephrol 2005;16:966-976.

14. Destro M, Cagnoni F, Dognini GP et al. Telmisartan: just an antihypertensive agent? A literature review. Expert Opin Pharmacother 2011;12:2719-2735.

15. Efrati S, Berman S, llgiyeav E et al. PPAR-gamma activation inhibits angiotensin II synthesis, apoptosis, and proliferation of mesangial cells from spontaneously hypertensive rats. Nephron Exp Nephrol 2007;106: e107-e112.

16. Xiao J, Leung JC, Chan LY et al. Crosstalk between peroxisome proliferator-activated receptor-gamma and angiotensin II in renal tubular epithelial cells in IgA nephropathy. Clin Immunol 2009;132: 266-276.

17. Sugawara A, Takeuchi K, Uruno A et al. Transcriptional suppression of type 1 angiotensin II receptor gene expression by peroxisome proliferator-activated receptor-gamma in vascular smooth muscle cells. Endocrinology 2001;142:3125-3134.

18. Ohga S, Shikata K, Yozai $\mathrm{K}$ et al. Thiazolidinedione ameliorates renal injury in experimental diabetic rats through anti-inflammatory effects mediated by inhibition of NF-kappaB activation. Am J Physiol Renal Physiol 2007;292:F1141-F1150.

19. Tilley DG, Nguyen AD, Rockman HA. Troglitazone stimulates beta-arrestin-dependent cardiomyocyte contractility via the angiotensin II type 1A receptor. Biochem Biophys Res Commun 2010;396:921-926.

20. Ketsawatsomkron P, Lorca RA, Keen $\mathrm{HL}$ et al. PPARgamma regulates resistance vessel tone through a mechanism involving RGS5-mediated control of protein kinase C and BKCa channel activity. Circ Res 2012;111:1446-1458.

21. Naito $\mathrm{T}, \mathrm{Ma} \mathrm{L}$, Yang $\mathrm{H}$ et al. Angiotensin type 2 receptor actions contribute to angiotensin type 1 receptor blocker effects on kidney fibrosis. Am J Physiol Renal Physiol 2010;298:F683-F691.

22. Todorov VT, Desch M, Schubert T et al. The Pal3 promoter sequence is critical for the regulation of human renin gene transcription by peroxisome proliferator-activated receptor-gamma. Endocrinology 2008;149:4647-4657.

23. Desch $M$, Schubert $T$, Schreiber $A$ et al. PPARgamma-dependent regulation of adenylate cyclase 6 amplifies the stimulatory effect of CAMP on renin gene expression. Mol Endocrinol 2010;24:2139-2151.

24. Toba $\mathrm{H}$, Miki $\mathrm{S}$, Shimizu $\mathrm{T}$ et al. The direct antioxidative and antiinflammatory effects of peroxisome proliferator-activated receptors ligands are associated with the inhibition of angiotensin converting enzyme expression in streptozotocin-induced diabetic rat aorta. Eur J Pharmacol 2006;549:124-132.

25. Dubey RK, Zhang HY, Reddy SR et al. Pioglitazone attenuates hypertension and inhibits growth of renal arteriolar smooth muscle in rats. Am J Physiol 1993;265:R726-R732.

26. Hayashi K, Kanda T, Homma K et al. Altered renal microvascular response in Zucker obese rats. Metabolism 2002;51:1553-1561.

27. Rodriguez WE, Tyagi N, Joshua IG et al. Pioglitazone mitigates renal glomerular vascular changes in high-fat, high-calorie-induced type 2 diabetes mellitus. Am J Physiol Renal Physiol 2006;291:F694-F701.

28. Arima $\mathrm{S}$, Kohagura $\mathrm{K}$, Takeuchi $\mathrm{K}$ et al. Biphasic vasodilator action of troglitazone on the renal microcirculation. J Am Soc Nephrol 2002;13: 342-349.

29. Liang $X B, M a ~ L J$, Naito $T$ et al. Angiotensin type 1 receptor blocker restores podocyte potential to promote glomerular endothelial cell growth. J Am Soc Nephrol 2006;17:1886-1895.

30. Palmer BF. Disturbances in renal autoregulation and the susceptibility to hypertension-induced chronic kidney disease. Am J Med Sci 2004;328:330-343.

31. Benigni A, Zoja C, Tomasoni $S$ et al. Transcriptional regulation of nephrin gene by peroxisome proliferator-activated receptor-gamma agonist: molecular mechanism of the antiproteinuric effect of pioglitazone. J Am Soc Nephrol 2006;17:1624-1632.

32. Kong $X$, Zhang DY, Wu HB et al. Losartan and pioglitazone ameliorate nephropathy in experimental metabolic syndrome rats. Biol Pharm Bull 2011;34:693-699.

33. Jin HM, Pan Y. Renoprotection provided by losartan in combination with pioglitazone is superior to renoprotection provided by losartan alone in patients with type 2 diabetic nephropathy. Kidney Blood Press Res 2007;30:203-211. 